\title{
GEOTURISMO PALEONTOLÓGICO NO CENTRO HISTÓRICO DO RIO DE JANEIRO
}

\author{
Marco André Malmann MEDEIROS ${ }^{1}$ \& Márcia Aparecida dos Reis POLCK \\ (1) Petrobrás, E\&P-EXP/AFOE/ADGP, Avenida República do Chile, 330, 15º andar, Centro, 20031-170, Rio de Janeiro, RJ. \\ Endereço Eletrônico: geomalmann@gmail.com. \\ (2) Departamento Nacional de Produção Mineral (DNPM), Avenida Nilo Peçanha, 50, $7^{\circ}$ andar, grupo 709, 713, Centro, 20044-900, \\ Rio de Janeiro, RJ. Endereço Eletrônico: marcia.reis@ dnpm.gov.br.

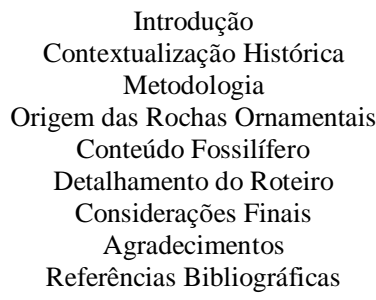

\begin{abstract}
RESUMO - Com o crescente aumento do geoturismo, roteiros geológicos com informações sobre rochas utilizadas nas fachadas de construções têm sido elaborados em vários lugares do mundo. O presente trabalho propõe um roteiro paleontológico, com base nos fósseis contidos nas rochas, presentes no revestimento e/ou piso de edifícios e monumentos do centro histórico da cidade do Rio de Janeiro, estabelecendo sua importância dentro de um contexto geológico, histórico e arquitetônico. Este roteiro paleontológico abrange nove pontos, iniciando pelo Chafariz do Mestre Valentim localizado na Praça XV de Novembro, e terminando na Igreja Nossa Senhora de Bonsucesso, situada no Largo da Misericórdia. Os fósseis identificados nas fachadas foram: estromatólitos, bivalves, bivalves rudistas radiolitídeos e caprinídeos, corais e esteiras algálicas e marcas de raízes contidas em calcário microbial. Além do cunho paleontológico, o presente trabalho também pode ser utilizado como recurso didático na divulgação e no ensino das geociências.
\end{abstract}

Palavras-chave: geoturismo, roteiro paleontológico, centro da Cidade do Rio de Janeiro.

ABSTRACT - With the increase in geotourism, geological walks with information about stones used in building facades have been developed in various parts of the world. This paper proposes a paleontological walk, based on the description of fossil-bearing rocks used in the coating and / or floors of buildings and monuments in historical downtown Rio de Janeiro, establishing its importance within a geological, historical and architectural context. The paleontological walk includes nine sites, starting at the Mestre Valentim`s Fountain located at Praça XV de Novembro, and ending at the Nossa Senhora de Bonsucesso Church, located at Largo da Misericordia. Fossils identified in the facades were stromatolites, bivalves, radiolitids and caprinids bivalves rudists, corals and algae mats and root marks contained in microbial limestone. Besides paleontological tourism, this paper can also be used as a teaching resource in the dissemination and teaching of geosciences.

Keywords: geotourism, paleontological walk, downtown Rio de Janeiro.

\section{INTRODUÇÃO}

Nas últimas décadas o geoturismo vem crescendo expressivamente e, através de sua prática e do consequente comércio de produtos relacionados, almeja-se atingir o desenvolvimento sustentável das populações envolvidas (Boggiani, 2010).

Roteiros geológicos com informações sobre rochas ornamentais em construções foram elaborados em vários lugares do mundo, tais como descritos por Baird (1968) e Bélanger (1998), em Quebec - Canadá; Robinson (1982, 1993), em Londres - Inglaterra; Silva (2007, 2009) e Cachão et al. (2009) em Almada, Lisboa e Setúbal, respectivamente - Portugal; incluindo, muitas vezes, informações sobre os fósseis contidos em fachadas e pisos.

No Brasil, o patrimônio cultural também tem sido mais valorizado com uma visão multidisciplinar, direcionando o olhar em especial para geologia, história, arquitetura, turismo e meio ambiente. Estudos desse tipo foram realizados por Stern et al. (2006), Fernandes et al. (2008), Augusto \& Del Lama (2011) e Kuzmickas \& Del Lama (2015), em São Paulo (SP); Mansur et al. (2008) e Almeida \& Porto Jr (2012), no Rio de Janeiro (RJ); Liccardo et al. (2008), em Curitiba (PR); Menezes (2007) e Pereira \& Liccardo (2010), em Minas Gerais; Pinto et al. (2010) e Pinto (2015), em Salvador (BA) e Carvalho (2010), em Natal (RN).

No Rio de Janeiro, a operação "Porto Maravilha", que está restaurando e revitalizando a região portuária, tem permitido criar novas condições de trabalho, moradia, transporte, cultura e lazer para os habitantes 
locais, além de fomentar expressivamente o desenvolvimento econômico da região (Silva, 2011, 2013). Com isso, o patrimônio histórico do centro da cidade do Rio de Janeiro valorizou bastante, chamando atenção também para o turismo nessa área.

O presente trabalho propõe um roteiro paleontológico, com base na descrição de fósseis contidos nas rochas utilizadas nos revestimentos e/ou pisos de edifícios e monumentos do centro histórico da cidade do Rio de Janeiro, estabelecendo sua importância dentro de um contexto histórico e arquitetônico e contribuindo para a geoconservação, educação e divulgação da paleontologia e para as geociências de modo geral.

\section{CONTEXTUALIZAÇÃO HISTÓRICA}

A fundação da cidade do Rio de Janeiro teve lugar inicialmente nas faldas do Morro Cara de Cão, sendo em seguida transferida para as planícies aluviais desenvolvidas no interior do recôncavo da Guanabara.

A refundação da cidade trouxe um problema para os colonizadores portugueses, a falta de material para a construção civil. Ao redor do Morro do Castelo existiam pântanos, mangues, lagunas, praias, rios e muita vegetação (Figura 1). Mas, embora fosse possível observar na região a existência de muitos penedos, estes eram constituídos por rochas muito mais duras que os calcários portugueses tradicionalmente utilizados em Portugal, além disso, faltavam aos colonizadores meios para explorá-las.

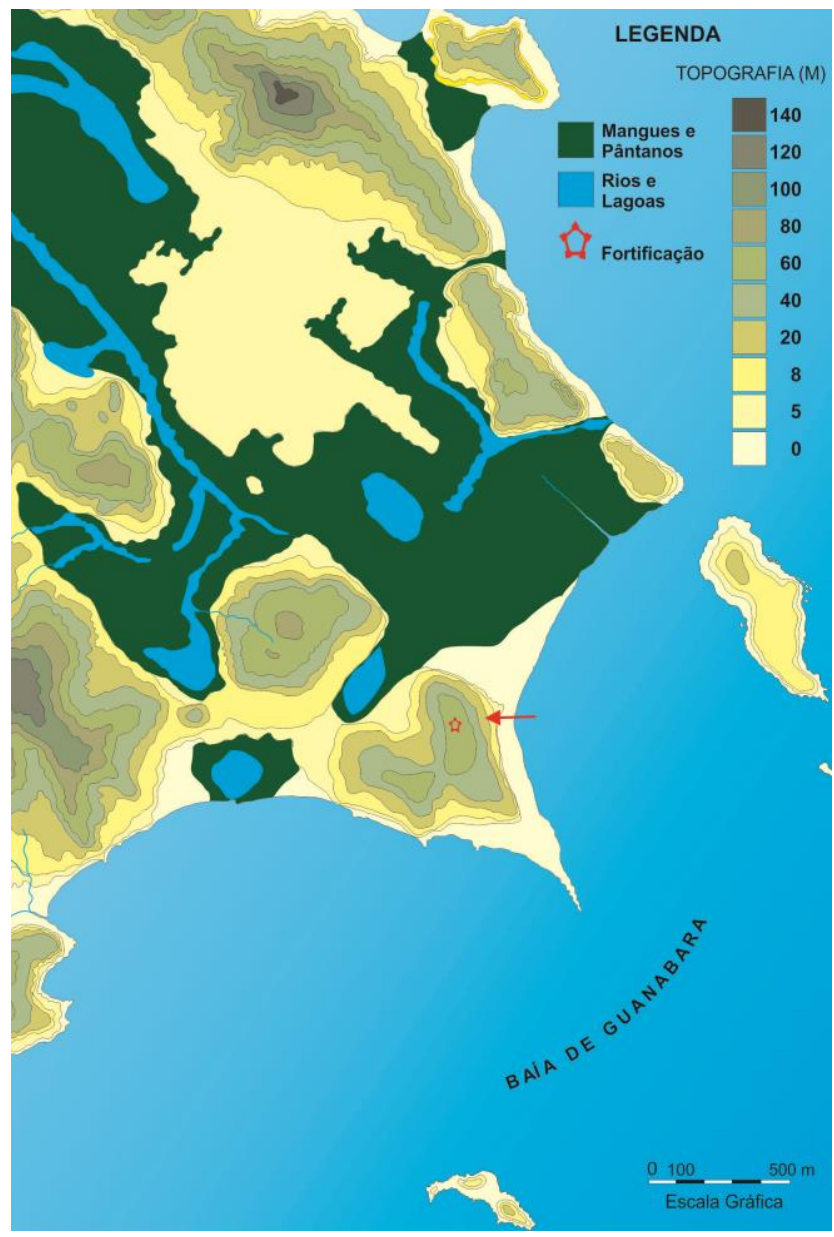

Figura 1. Paleogeografia do entorno do Morro do Castelo quando da refundação da cidade do Rio de Janeiro em 1565. Seta vermelha mostra "La Briqueterie" (Modificado de Barreiros, 1965).

As primeiras construções dos colonizadores europeus provavelmente foram feitas em madeiras ou em Taipa em "Pau-a-
Pique", um processo milenar de construção que os Portugueses trouxeram para o Brasil. As primeiras edificações de tijolos foram iniciadas 
em meados de 1556, com a chegada dos franceses, que tentaram estabelecer, uma colônia em terra firme denominada de "Henriville". Os tijolos eram fabricados em uma olaria localizada na atual Praia do Flamengo, entre a foz do Rio Carioca e o Outeiro da Glória, assinalada nas ilustrações da época como "briqueterie" (Lery, 1941; Thévet, 1944).
A indicação nos mapas feitos por Pierre Duval em 1562, sobre as informações de Jean de Léry e Nicolas Durand de Villegagnon o período de 1557/1558, da "briqueterie" (Figura 2) implica que as primeiras explorações minerais, que tiveram lugar no Rio de Janeiro, estavam relacionadas à exploração das argilas para a fabricação dos tijolos e telhas (Léry, 1941).

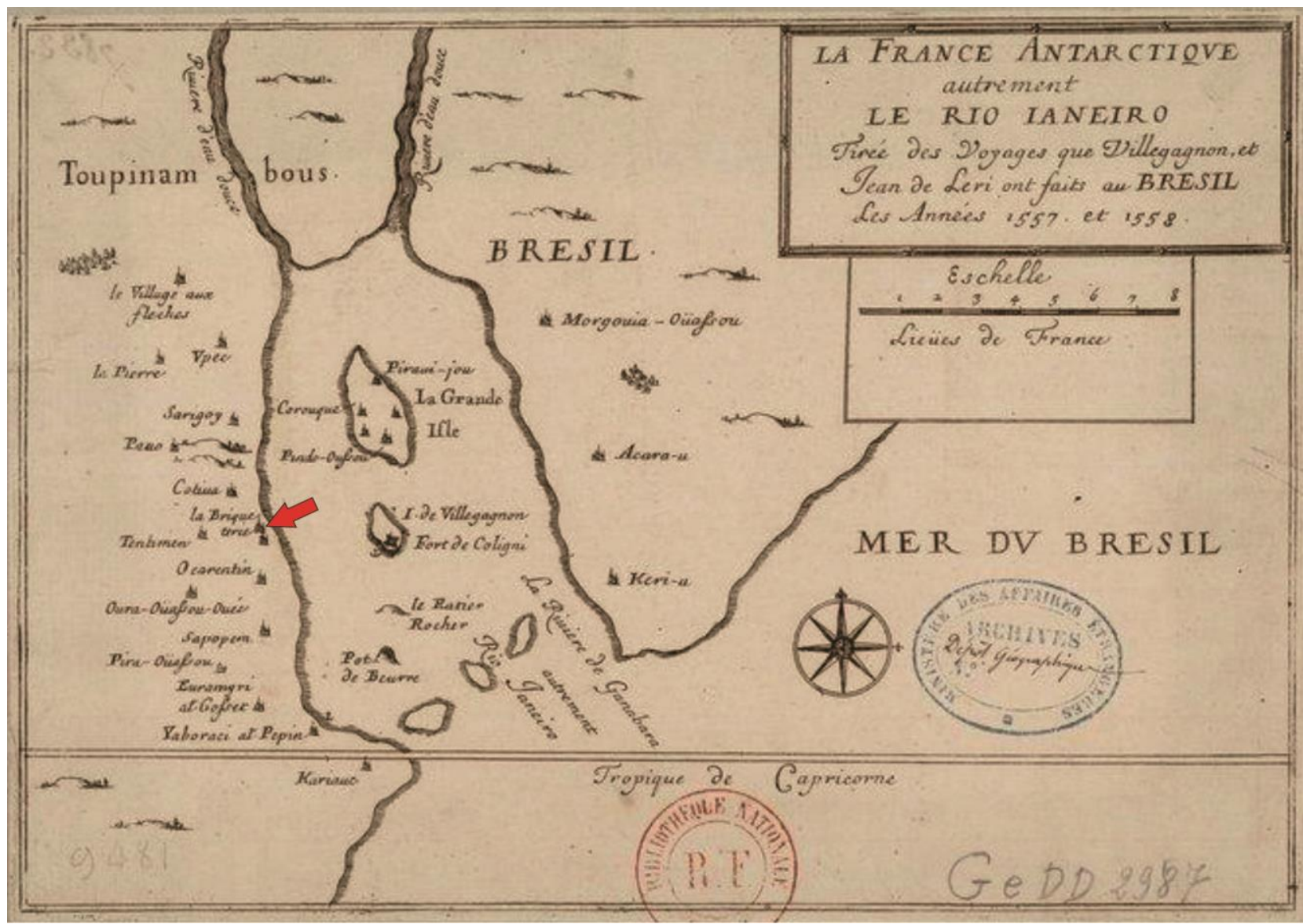

Figura 2. Mapa localizando a primeira exploração mineral da cidade do Rio de Janeiro, denominada "La Briqueterie" (seta vermelha) (Modificado de Léry, 1941).

As primeiras construções em pedra do Rio de Janeiro foram feitas com os calcários trazidos como lastro nas naus portuguesas e cimentadas com argamassa, dando origem a paredes muito espessas.

Os primeiros registros de exploração de pedreiras para fornecimento de material de construção civil são do início do século XVII, quando religiosos do Convento do Carmo obtiveram autorização formal do governo para explorar as rochas da Ilha da Enxada para uso em obras do convento e de sua nova igreja (Azevedo, 1877; Mello Morais, 1886). Ainda assim, no período colonial, o uso de rochas que apresentavam função estética, como molduras de portas, janelas ou cantarias decorativas que, demandavam mão-de-obra especializada, eram de Portugal, que exportou largamente para o Brasil, nos séculos XVI-XVII, o Calcário Lioz da região de Pêro Pinheiro (Brandão, 1996).

Até a chegada da Família Real em 1808, o Rio de Janeiro não possuía muitas construções em cantaria, afora igrejas e parcas construções oficiais. Todavia, durante o reinado de Dom João VI, entre 1808 e 1821, ocorreu um acelerado crescimento urbano e, graças às melhorias realizadas, as rochas passaram a ser usadas de forma mais efetiva, em especial no calçamento da cidade, aumentando a 
importância das pedreiras como fonte de matéria prima (Almeida \& Porto Jr, 2012).

A partir do século XX, a utilização de cantaria, mesmo ornamental, passou a ser substituída pelo concreto e os pavimentos de pedra foram sucedidos pelos ladrilhos hidráulicos. Entretanto, as rochas voltaram a ser utilizadas como revestimento externo e pavimentos, como observado nos edifícios do entorno da Praça Serzedelo Correia em Copacabana, ou em prédios públicos (como os construídos durante o período do Estado Novo na Esplanada do Castelo no Centro do Rio de Janeiro), ocorrendo um aumento na importação de placas de "mármores" europeus, em especial de Portugal e Itália.

\section{METODOLOGIA}

Para a realização deste trabalho foi feita uma prospecção inicial nas fachadas e pisos de edifícios e monumentos em parte do centro histórico da cidade do Rio de Janeiro com o intuito de cadastrar rochas contendo fósseis. Tanto os revestimentos quanto os pisos foram fotografados digitalmente, descritos no aspecto geológico e identificados os seus respectivos fósseis. A identificação dos Moluscos fósseis foi baseada em Dechaseaux et al. (1969) e
Steuber e Löser (2000) e as estruturas dos estromatólitos foi baseada em Srivastava (2004). A associação com o estilo arquitetônico e a importância histórica, assim como a região de origem dos litotipos, quando possível, foram realizados com base na bibliografia existente. $\mathrm{O}$ roteiro propriamente dito foi traçado buscando um percurso mais rápido, ou seja, a proximidade entre cada ponto e a possibilidade de ser realizado a pé.

\section{ORIGEM DAS ROCHAS ORNAMENTAIS}

Até a primeira metade do século XIX, as rochas mais frequentemente utilizadas para a construção da cidade eram o Gnaisse Facoidal e os leptinitos, utilizados tanto de forma estrutural, como de cantaria, em especial em pisos e batentes de portas e janelas. Os detalhes ornamentais eram trazidos de Portugal e normalmente constituídos com calcários cenomanianos da região de Pero Pinheiro e Terrugem, denominados de Lioz.

A partir da segunda metade do século XIX, outras rochas passaram a ser utilizadas nas construções, em especial mármores italianos. O século XX inicia e a cidade do Rio de Janeiro passa por grandes modificações com as reformas urbanas levadas a cabo pelo prefeito Pereira Passos. A abertura da Avenida Central, atual Avenida Rio Branco, resultou nas construções de prédios modernos, cujo interior foi adornado com pisos e, ocasionalmente, outros elementos arquitetônicos em pedras, normalmente trazidas da Europa, embora não mais apenas de Portugal. Os mármores brasileiros de Minas Gerais, granitos, dioritos e outras litologias, principalmente da região Sudeste, começaram a ser utilizados.

A segunda metade do século XX, em especial da década de 1960 em diante, as rochas ornamentais passaram a serem usadas em profusão, principalmente como piso e revestimento externo. A procedência destas rochas ornamentais tornou-se quase impossível de ser determinada, visto que muitos países, tais como Itália, Portugal, Espanha e Argentina passaram a fornecer para o Brasil, sendo a origem reconhecida somente por suas características paleontológicas e petrográficas.

No âmbito do roteiro proposto, os principais litotipos observados são: calcários de idades jurássicas e cretácicas (cenomanianas) de Portugal - Lioz (Figura 3), travertino de idade cenozoica da Itália (Figura 4) e metacalcário de idade paleoproterozoica da Pedreira do Cumbi, em Cachoeira do Campo, na Fazenda do Cumbi, ao sul de Ouro Preto, Minas Gerais, Sudeste do Brasil (Figura 5). 


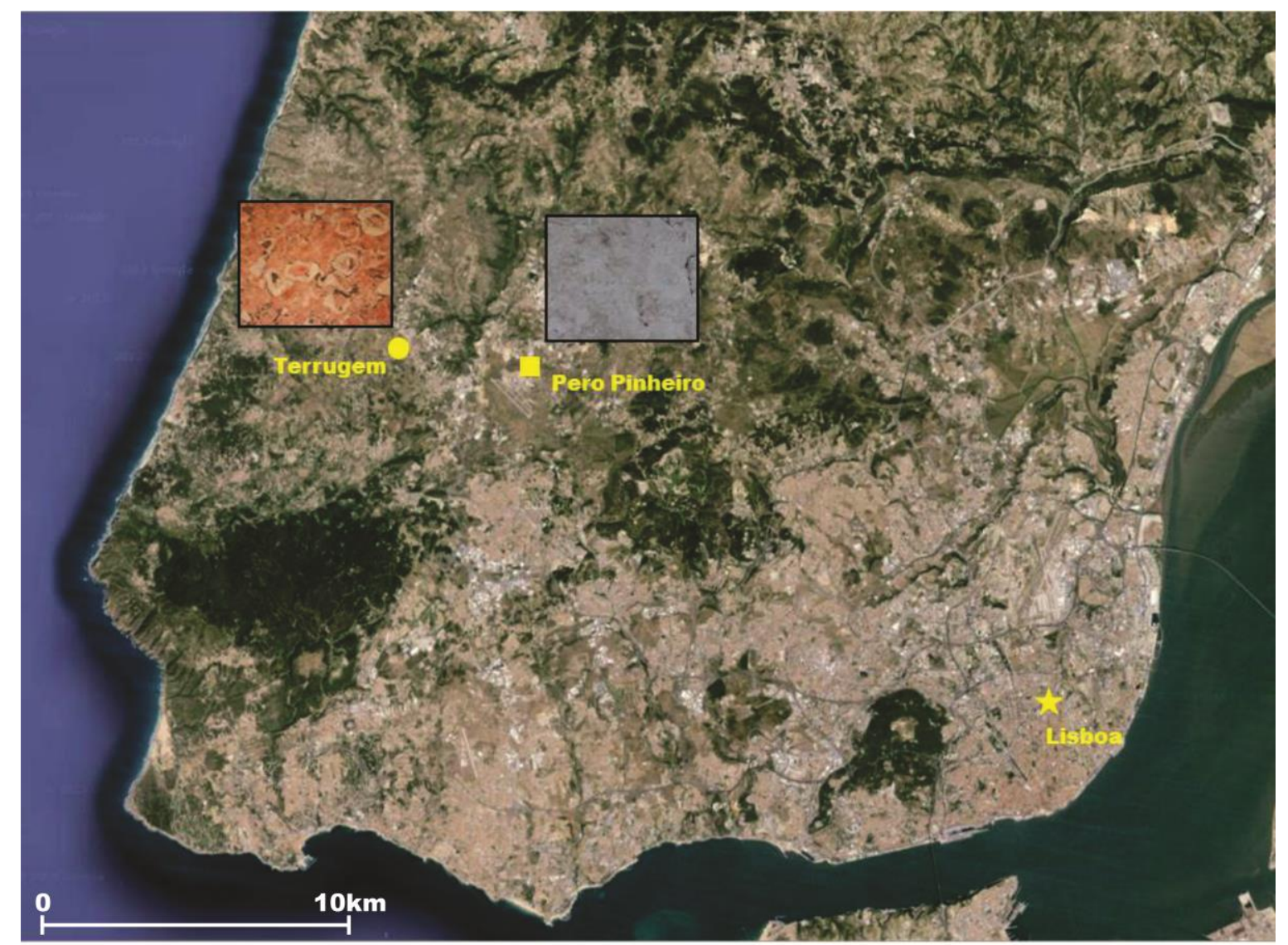

Figura 3. Mapa de localização das áreas produtoras dos calcários cenomanianos em Portugal, destacando a litologia de cada região. Extraído de https://maps. google.com.br/(Google Maps).

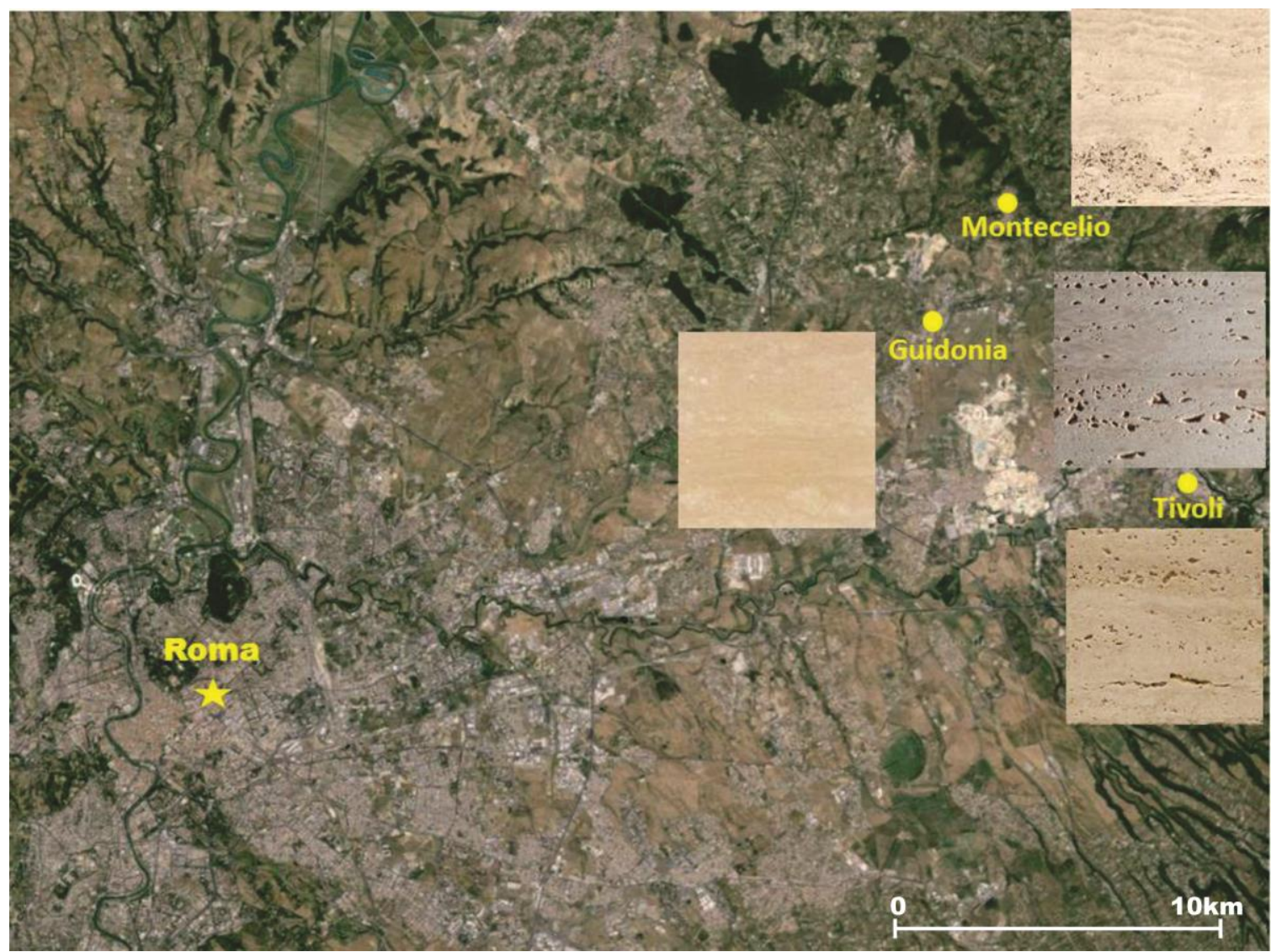

Figura 4. Mapa de localização das áreas produtoras de travertinos na Itália, destacando as diferentes estruturas de cada região. Extraído de https://maps. google.com.br/(Google Maps). 


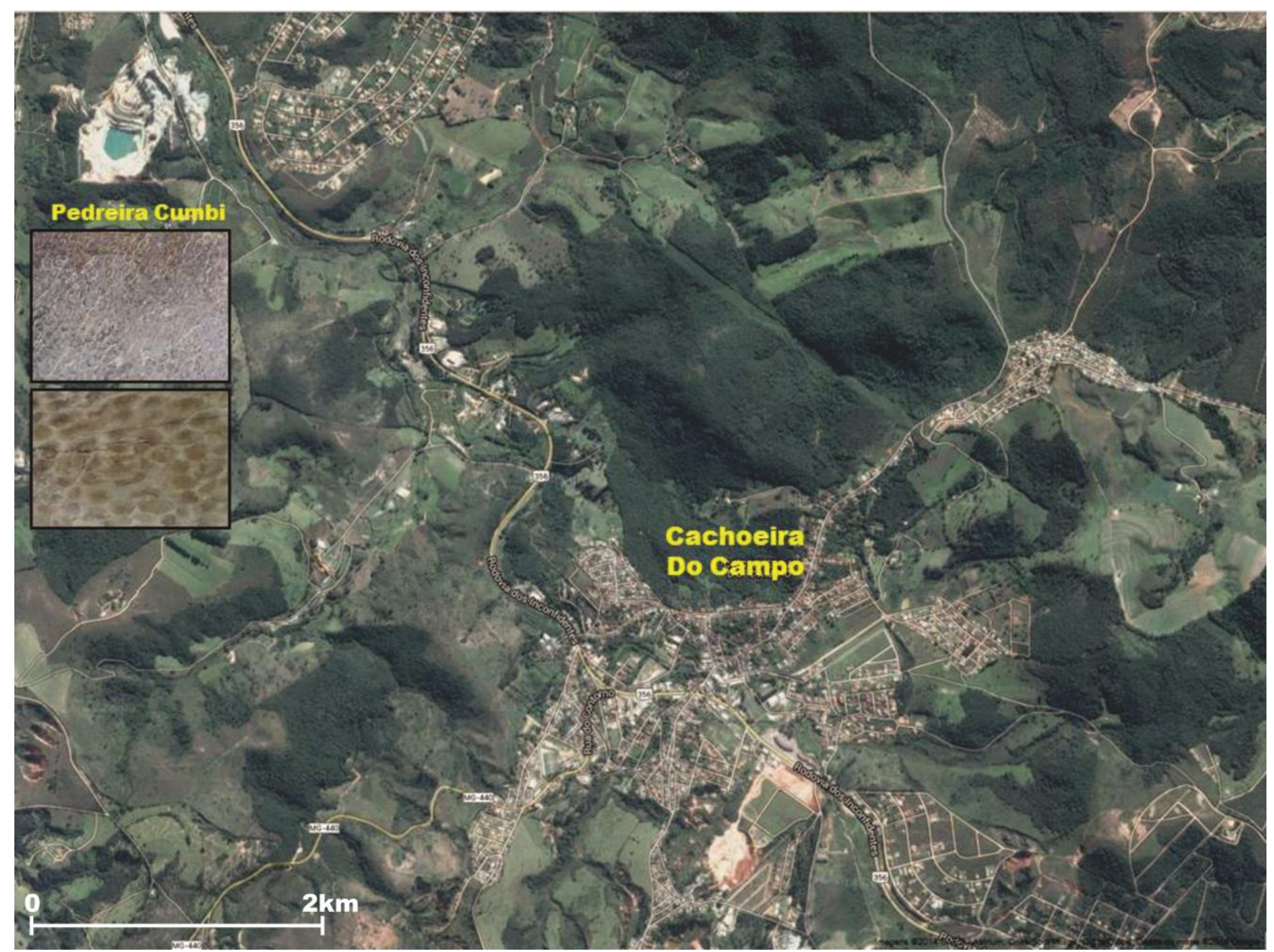

Figura 5. Mapa de localização da área produtora dos calcários paleoproterozoicos em Minas Gerais, Brasil, destacando o litotipo utilizado. Extraído de https://maps. google.com.br/(Google Maps).

\section{CONTEÚDO FOSSILÍFERO}

Ao longo da trajetória, os seguintes fósseis foram identificados nas fachadas e pisos dos edifícios descritos: bivalves rudistas radiolitídeos e caprinídeos, estromatólitos, corais e esteiras algálicas contidas em calcário microbial.

Os bivalves rudistas existiram do Jurássico Superior ao final do Cretáceo e se diferenciavam dos outros bivalves principalmente pelo seu desenvolvimento e por apresentarem conchas muitas vezes grandes (Steuber \& Löser, 2000). Esses moluscos formavam frequentemente grandes aglomerados que ocupavam extensas áreas dos fundos marinhos rasos de águas mornas e sua presença nas rochas encontradas em Lisboa indica que na região existiu um mar tropical costeiro pouco profundo. Durante o Cenomaniano, a Península Ibérica estava localizada mais próxima da linha do Equador, em latitudes mais baixas que as de hoje, ou seja, na margem do Mar de Tétis, que corresponde ao proto-Mediterrâneo (Silva, 2007).

Os rudistas encontrados pertencem à Família †Radiolitidae, gênero †Radiolites Lamarck, 1801 e à Família †Caprinidae e gênero †Caprinula D’Orbigny, 1847.

Os rudistas radiolitídeos apresentam concha fortemente inequivalente, com a valva fixa cônica, retilínea, foliácea, ornamentada por fortes pregas transversais, mais ou menos onduladas, semelhante a uma pilha de cones invertidos. As bandas sifonais longitudinais são estreitas. A valva livre possui forma de opérculo, convexa ou achatada. Esses moluscos eram sésseis epibentônicos, cimentados ao substrato pela valva fixa, suspensívoros e viviam em ambientes marinhos bentônicos, infralitorais, para-recifais, de águas quentes e de salinidade normal (Dechaseaux et al., 1969) (Figura 6). 


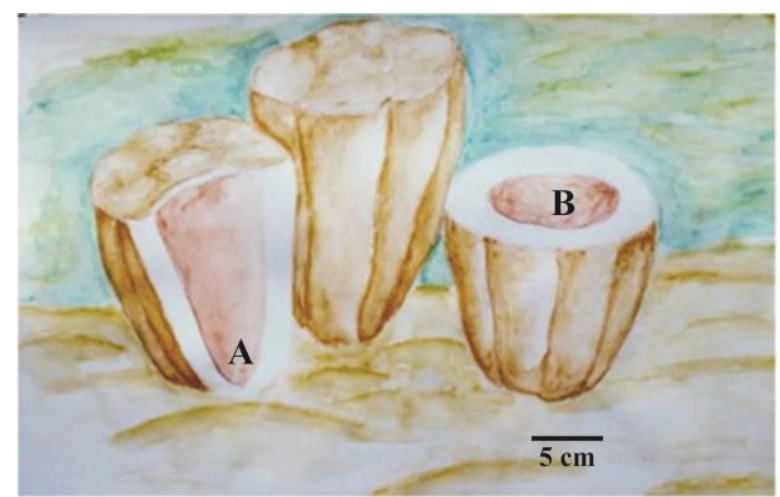

Figura 6. Reconstrução de rudistas radiolitídeos. A. Corte longitudinal. B. Corte transversal.

Os rudistas caprinídeos possuíam conchas formadas por duas valvas diferentes, sendo que uma delas, que se enterrava no substrato, era cônica e a outra era livre e enrolada em forma de "chifre de cabra". As paredes das valvas possuíam canais, muitas vezes visíveis nos fósseis (Figura 7). Em relação à sua paleoecologia eram epibentônicos sésseis e suspensívoros. Viviam em ambientes marinhos bentônicos, infralitorais, para-recifais, de águas quentes e de salinidade normal (Dechaseaux et al., 1969; Silva, 2007).

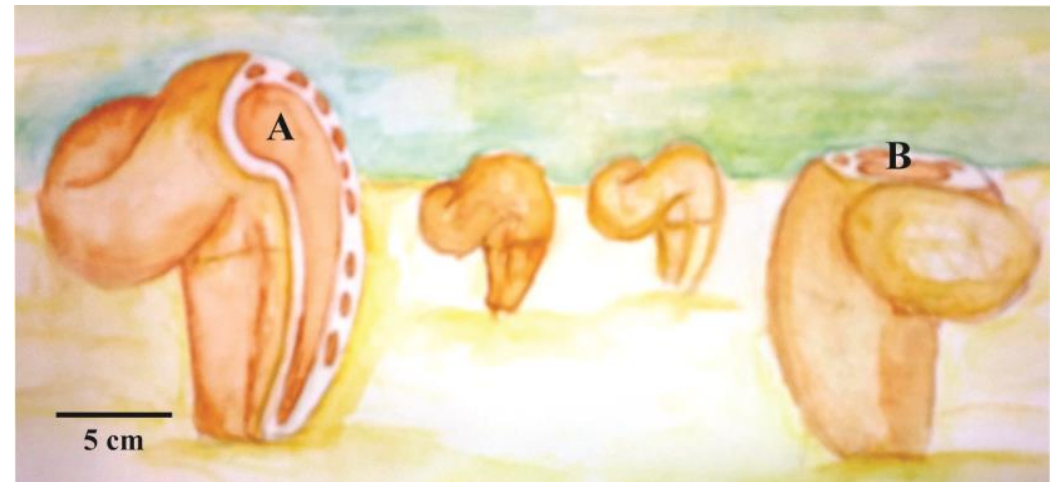

Figura 7. Reconstrução de rudistas caprinídeos. A. corte longitudinal. B. corte transversal.

Os estromatólitos, ou seja, estruturas biossedimentares formadas através de atividades microbianas (cianobactérias) nos ambientes aquáticos (Srivastava, 2004), tiveram um papel importantíssimo para a evolução da vida na Terra, visto que durante o Précambriano as cianobactérias, que realizam fotossíntese, foram as responsáveis pelo aumento da taxa de oxigênio marinho e posteriormente terrestre. Eles estão preservados em metacalcários de coloração rosada, branca e cinza clara, apresentando formas entre circulares e elípticas densamente agrupadas, quando o corte é transversal e faixas paralelas não uniformes, quando o corte é longitudinal (Figura 8). A laminação interna foi quase toda destruída pela recristalização da rocha. Esses estromatólitos de idade paleoproterozoica do Supergrupo Minas, Formação Fecho do Funil, apresentam idades variando entre 2,22 e 2,10 Ga (Babinski et al., 1995), encontrando-se entre os mais antigos fósseis do Brasil e foram também identificados por Sallun Filho e Fairchild (2005) em pisos do Shopping Ibirapuera e Eldorado, em São Paulo. 


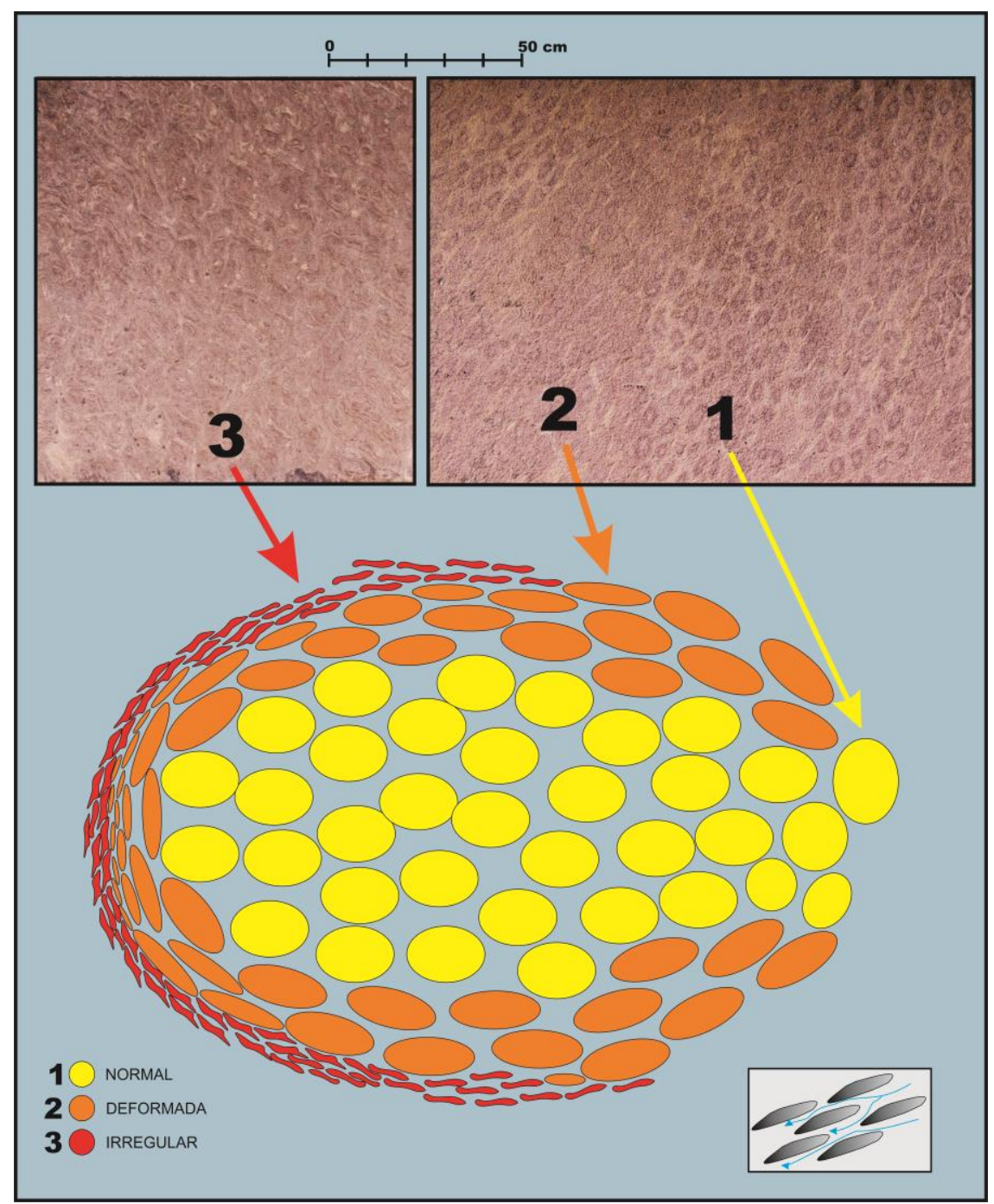

Figura 8. Estromatólitos e suas formas.

\section{DETALHAMENTO DO ROTEIRO}

O roteiro paleontológico localiza-se próximo à área de revitalização e restauração da Zona Portuária do Rio de Janeiro, e conta com muitas opções de transporte, inclusive o sistema de barcas para a Ilha do Governador e Niterói.

O percurso proposto (Figura 9), elaborado para ser realizado em um espaço de tempo curto ao redor de 1 hora à 1 hora e 30 minutos, contempla prédios com interesse histórico/arquitetônico e paleontológico, abrangendo nove pontos: 1) Chafariz do Mestre Valentim, 2) Tribunal de Justiça, 3) Tabacaria Africana, 4) Igreja da Ordem $3^{\mathrm{a}}$ do Carmo, 5) Rua da Assembleia no 31 e Rua do Carmo no 8, 6) Superintendência Regional da Receita Federal, 7) Tribunal Regional do Trabalho, 8) Hospital Geral da Santa Casa da Misericórdia, 9) Igreja Nossa Senhora de Bonsucesso.
Os pontos selecionados apresentam uma diversidade de fósseis, idades e ambientes de sedimentação distintos. Percorrendo a área, é possível observar que os litotipos são agrupados segundo a época de construção dos prédios, assim, a relação entre o contexto histórico e a arquitetura da época está retratada nos materiais utilizados para sua construção ou adorno. As edificações feitas até o segundo império possuem rochas trazidas de Portugal, enquanto que as do final do segundo império e início da primeira república utilizavam rochas importadas da Itália. Durante a Era Vargas (1930-1945), o nacionalismo econômico passou a imperar e as construções utilizavam rochas ornamentais brasileiras, em especial do Sudeste do Brasil. 


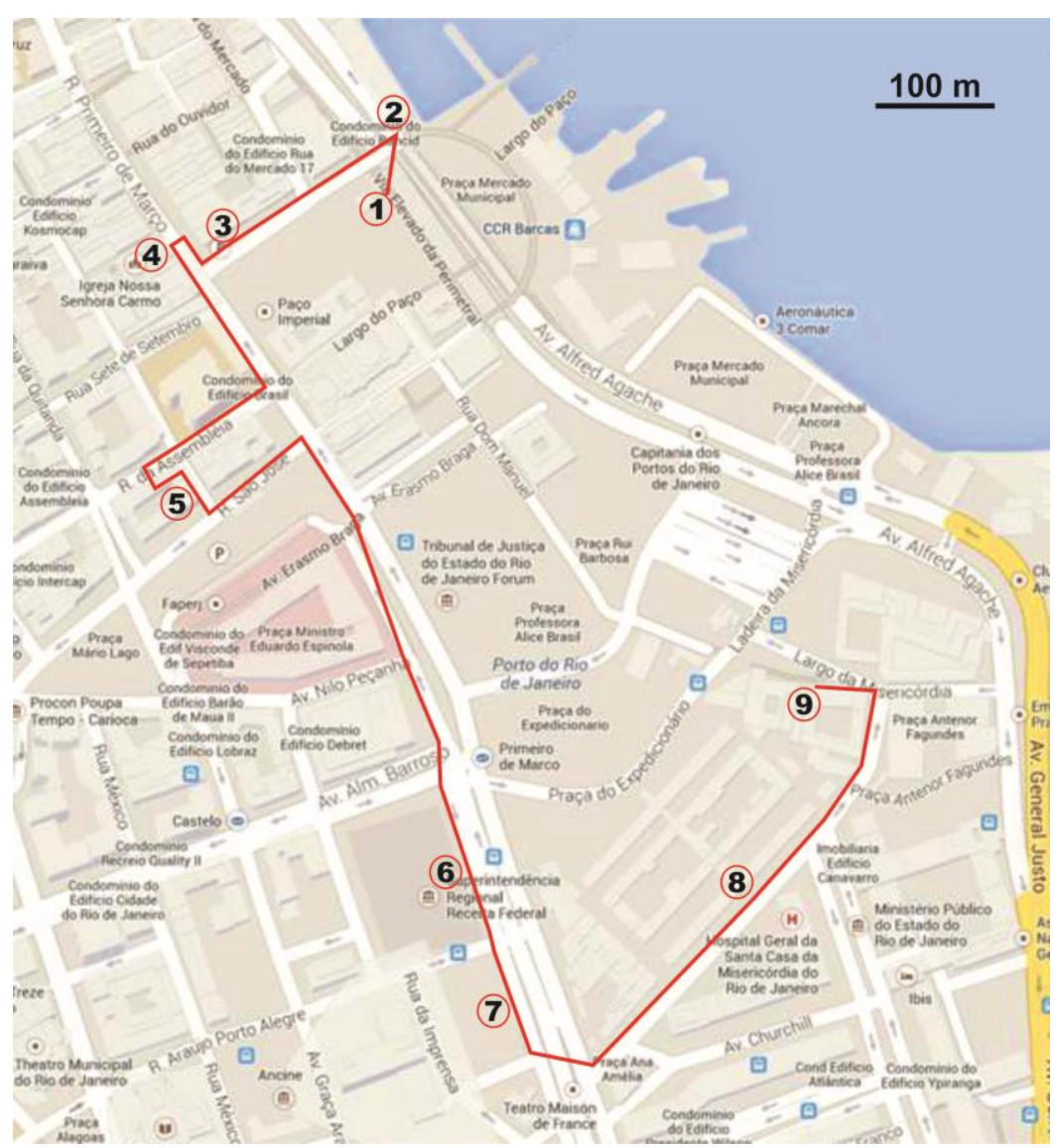

Figura 9. Roteiro geoturístico proposto para o centro histórico da cidade do Rio de Janeiro. Extraído de https://maps. google.com.br/(Google Maps).

Em função do emprego de materiais diversos, hoje é possível reconhecer variados registros paleontológicos como: estromatólitos, bivalves, bivalves rudistas radiolitídeos e caprinídeos, marcas de raízes (Tabela 1).

\begin{tabular}{|c|c|c|c|c|c|}
\hline ROCHA & IMAGEM & ORIGEM & IDADE & FÓSSEIS & AMBIENTE \\
\hline Calcário Lioz & & Portugal & Jurássico & Bivalves Rudistas & Recifes \\
\hline Calcário Encarnadão & & Portugal & Cretáceo (Cenomaniano) & Bivalves Rudistas & Recifes \\
\hline Turfa Calcária & & Itália & Cenozoico & Bivalves, Raízes, Estromatólitos & Lagos \\
\hline Travertino & & Itália & Cenozoico & Ocasionais estromatólitos & Lagos \\
\hline Metacalcário & & Brasil (Minas Gerais) & Paleoproterozoico & Estromatólitos & Recifes \\
\hline
\end{tabular}

Tabela 1. Tabela mostrando os principais litotipos do roteiro, com as respectivas proveniências, idades, fósseis e ambientes sedimentares. 


\section{Ponto 1: Chafariz do Mestre Valentim - Praça XV de Novembro S/N.}

Em 1747, o governador Gomes Freire de Andrade, Conde de Bobadela, colocou, no meio do antigo Largo do Carmo, um elegante chafariz importado de Lisboa. A água proveniente do chafariz do Largo da Carioca e conduzida por um cano de pedra era oriunda do Rio Carioca. No governo do Vice-Rei Dom Luis de Vasconcelos, em 1779, foi construído um cais de pedra no limite do antigo largo, com três escadas para o mar e uma rampa. O chafariz foi então, reformado por completo e deslocado do centro da praça para a beira do mar e inaugurado, somente em 1789, com a finalidade de abastecer principalmente as embarcações. Essa reforma foi realizada por Valentim da Fonseca e Silva, conhecido como Mestre Valentim, artista mineiro, filho de escrava, que realizou no Rio de Janeiro, na metade do século XVIII, trabalhos decorativos de madeira, prata e pedra, com riqueza de detalhes e bom gosto.
Este importante marco da história do Rio antigo apresenta corpo e ornamentos maiores (pirâmide acima do patamar) compostos por blocos de Gnaisse Facoidal em forma de prisma. Os ornamentos menores que encimam a construção foram confeccionados em calcário branco Lioz, formado durante o Cretáceo nos arredores de Pêro Pinheiro, entre Lameiras e Negrais, cerca de $50 \mathrm{~km}$ a Norte de Lisboa. A coloração esbranquiçada do calcário indica um ambiente aquático, oxidante, de pequena profundidade e de forte energia hidrodinâmica (Cachão et al., 2009).

É possível observar bivalves rudistas em cortes transversais (balaustrada, pináculos em forma de chamas, barras e florões), pertencentes à Família †Radiolitidae, gênero $\dagger$ Radiolites Lamarck, 1801. Os fósseis desses bivalves são aqui encontrados em seção transversal, com diâmetro de aproximadamente 5 a $10 \mathrm{~cm}$, e se evidenciam em função da parede de suas conchas serem espessas e maciças (Figura 10).

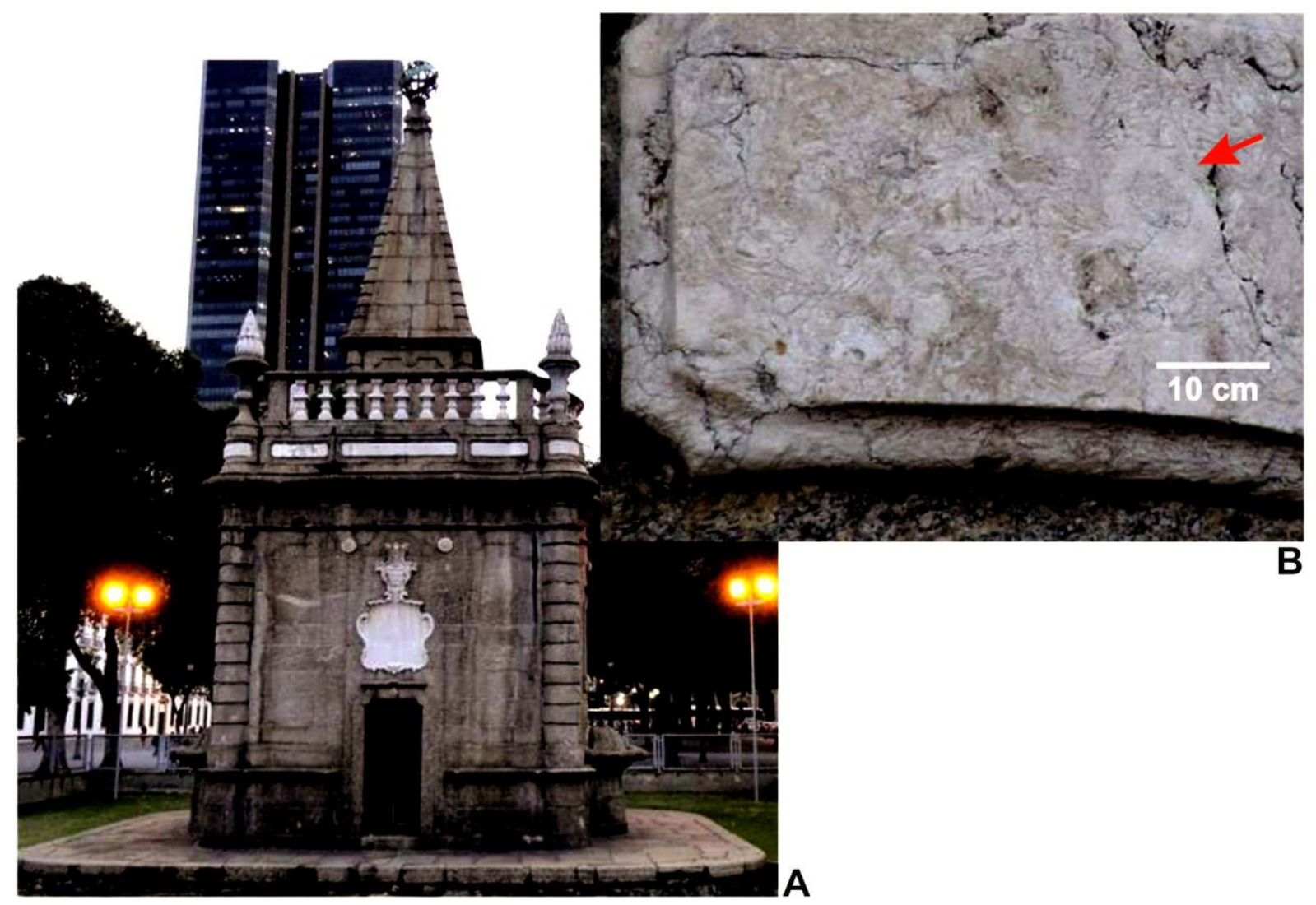

Figura 10. A. Chafariz do Mestre Valentim. B. Destaque maior mostra o Calcário Lioz com cortes transversais dos rudistas radiolitídeos (seta vermelha). 


\section{Ponto 2: Tribunal da Justiça - Praça XV de Novembro, $\mathbf{n}^{0} 2$.}

Foi criado para abrigar o antigo Entreposto Federal de Pesca, inaugurado em 1941, e posteriormente, abrigou a Companhia Nacional de Abastecimento (CONAB). Em maio de 2005, foi cedido em comodato ao Tribunal da Justiça, pelo prazo de 50 anos, pelo prefeito César Maia.

A ornamentação do prédio foi feita pelo escultor Armando Schnoor, que mostra tradições classistas e naturalistas, além de certas influências das correntes modernas de seu tempo, como as formas geometrizantes do gosto cubista que embasa a Art Decó.

A rocha que reveste tanto o piso quanto a metade inferior das paredes de todos os andares é um metacalcário de coloração amarelada, provavelmente proveniente da Pedreira do Cumbi, Minas Gerais. Nesse mármore observam-se estromatólitos, ou seja, estruturas biossedimentares formadas através de atividades microbianas (cianobactérias) nos ambientes, sendo possível observar tanto cortes longitudinais, semelhantes a faixas paralelas (Figuras 11 A e B), como transversais, apresentando formas aproximadamente circulares (Figura $11 \mathrm{C}$ ).
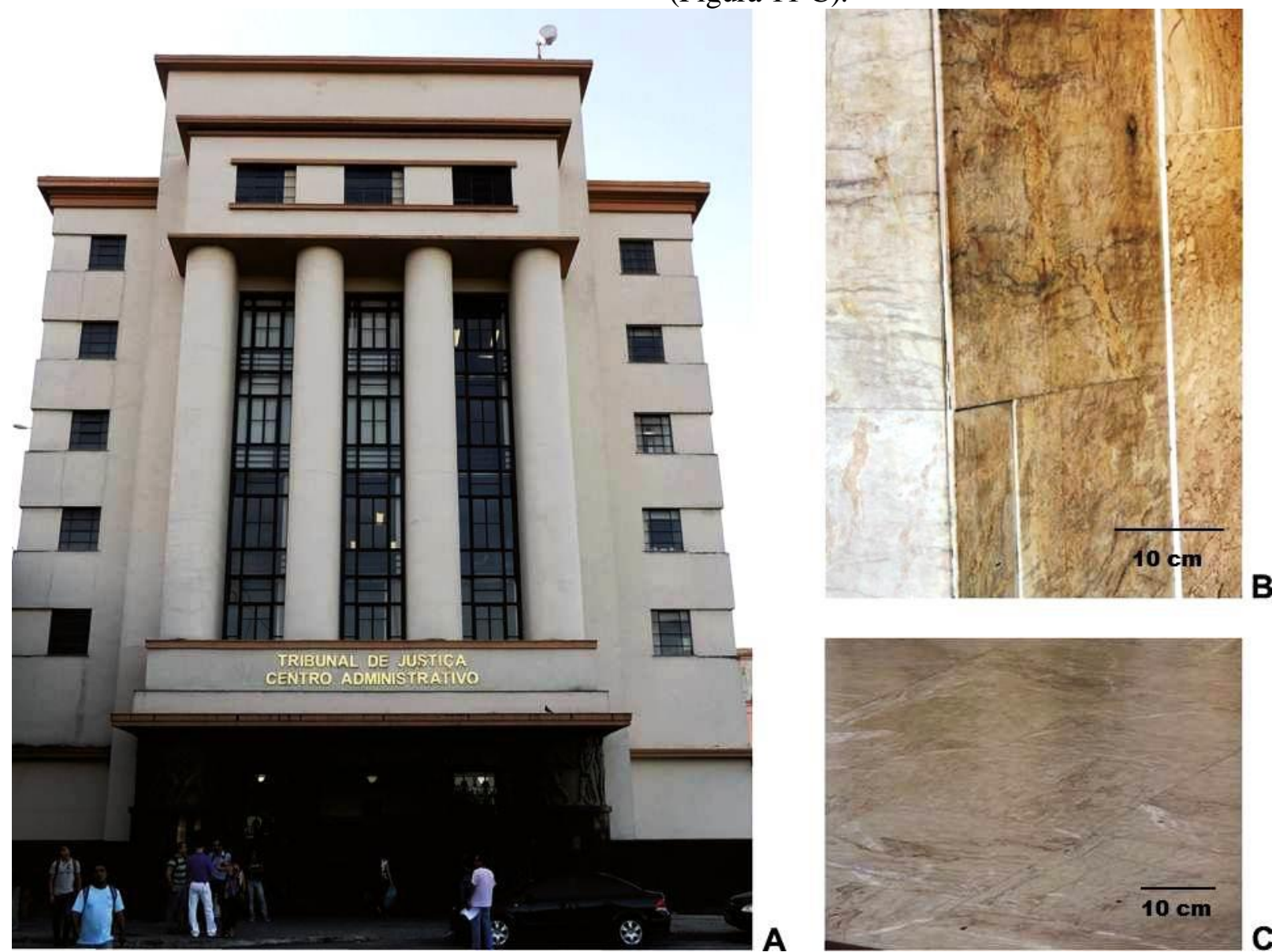

Figura 11. A. Tribunal de Justiça. B. Paredes com estromatólitos em cortes longitudinais. C. Piso com estromatólitos em cortes transversais.

\section{Ponto 3: Tabacaria Africana - Praça XV de Novembro, 38.}

O terceiro ponto é representado pela Tabacaria Africana, frequentada pela elite do segundo império, inclusive pelo Imperador D. Pedro II. Foi fundada em 1846 e possui o título de casa comercial mais antiga da cidade.

Sua fachada apresenta um revestimento de dois calcários fossilíferos, separados por uma faixa de calcário preto (Figuras 12 A e B).
$\mathrm{Na}$ sua parte inferior, observa-se, como revestimento, um calcário rosa, fossilífero, ainda hoje explorado nas regiões de Terrugem e Pêro Pinheiro, ao norte de Lisboa, com o nome comercial de calcário Encarnadão. De acordo com Cachão et al. (2009), estes calcários de idade cenomaniana, apresentam esta coloração rosa, em função da presença de óxido de ferro, indicando deposição em ambiente oxidante. 
A assembleia fossilífera observada inclui bivalves rudistas pertencentes à Família $\dagger$ Radiolitidae, gênero $†$ Radiolites Lamarck, 1801, na parte inferior. Na parte superior, o revestimento é composto por um Calcário Lioz de cor clara (branco a bege), rico em fósseis de bivalves rudistas pertencentes à Família $\dagger$ Caprinidae, gênero †Caprinula D’Orbigny, 1847 (Figuras $12 \mathrm{~B}$ e C).
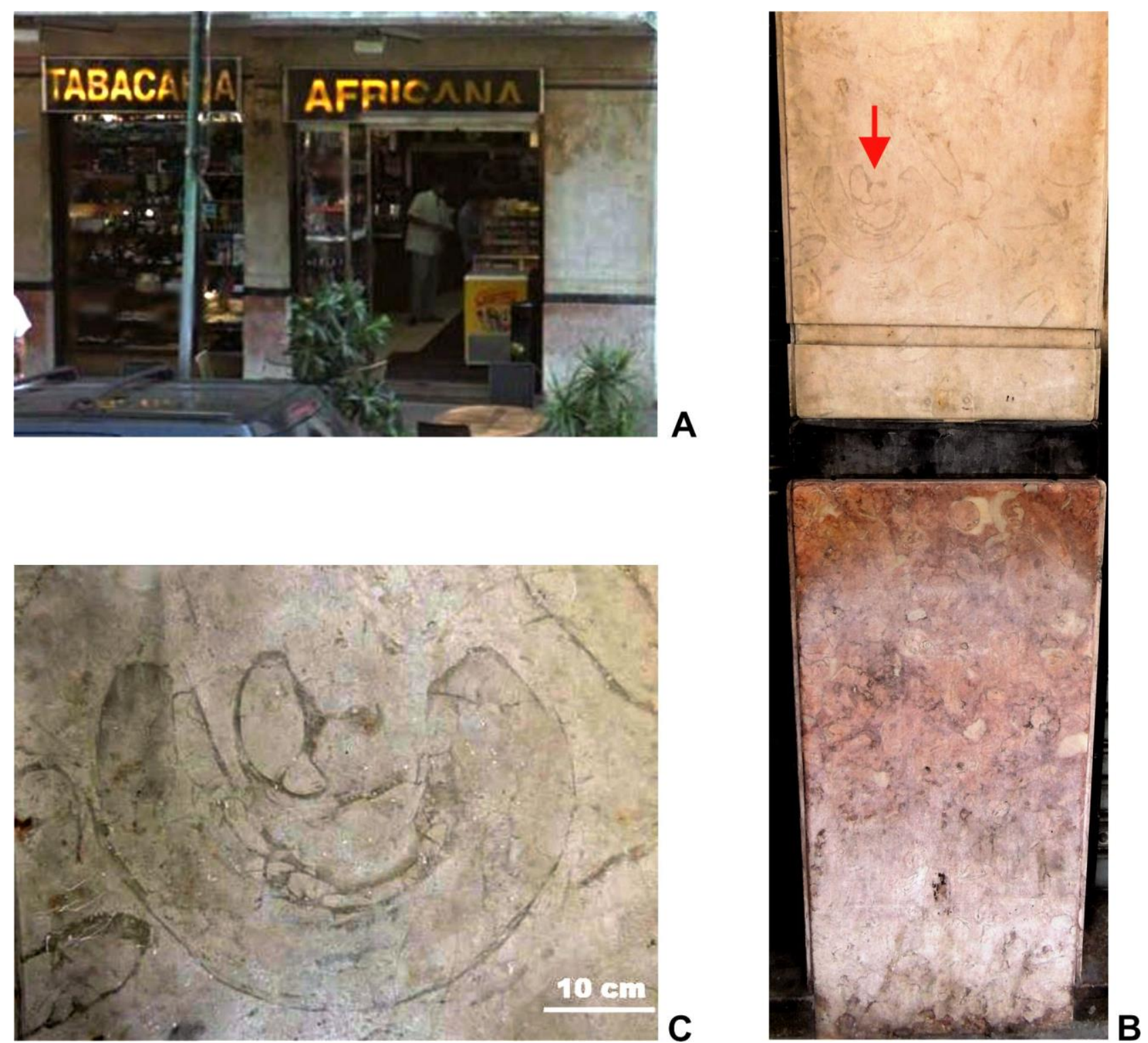

Figura 12. A. Fachada da Tabacaria Africana. B. Coluna com revestimento de dois diferentes tipos de calcários fossilíferos (seta vermelha mostra detalhe do fóssil). C. Detalhe do fóssil rudista caprinídeo em corte longitudinal.

\section{Ponto 4: Igreja Ordem Terceira do Carmo - Rua Primeiro de Março.}

A Ordem Terceira de Nossa Senhora do Monte do Carmo foi fundada em 9 de julho de 1648. Em 1749, a ordem decidiu edificar uma nova capela que servisse para os serviços espirituais de uma maneira mais confortável e somente em 1752, encomendou a cantaria de mármore destinada à capela-mor. Os alicerces da nova igreja foram iniciados em 1755 e finalmente, em 22 de julho de 1770, o novo templo sagrado foi inaugurado, em procissão solene, com as imagens que guarneciam a capela velha, com realce para a de Nossa Senhora do Carmo e a do Santíssimo Sacramento. As duas torres imponentes, revestidas de azulejos azuis, foram concluídas apenas em 1849 e 1850, respectivamente, tendo sido anteriormente construído um campanário provisório, em madeira, onde foram instalados os sinos do Convento, que fora transformado em residência oficial da Família Real, quando de sua vinda para o Brasil. 
A fachada de pedra (Figura 13A), que prenuncia o estilo neoclássico, tem uma porta com linha de composição típica do século XVIII. A decoração é fitomorfa, em margaridas, flor característica do período. Um medalhão de Calcário Lioz, feito em Lisboa, com uma imagem de Nossa Senhora do Carmo, o Menino Jesus ao colo, entregando o escapulário do Carmo a São Simão Stock, completa sua decoração.

$\mathrm{Na}$ cantaria da porta principal (Figura 13 B), também composta por um Calcário Lioz branco, é possível observar fósseis de bivalves rudistas identificados como pertencentes à Família †Caprinidae e gênero †Caprinula D Orbigny, 1847, em função de apresentarem parede da valva livre com uma série de canais paliais internos com formas poligonais e uma série exterior de canais piriformes (Figuras 13 $\mathrm{C}$ e D). Esses fósseis diferem do gênero $\dagger$ Caprina D`Orbigny, 1822, cuja parede da valva livre possui uma ou duas séries de canais paliais piriformes nas regiões anterior, ventral e posterior.
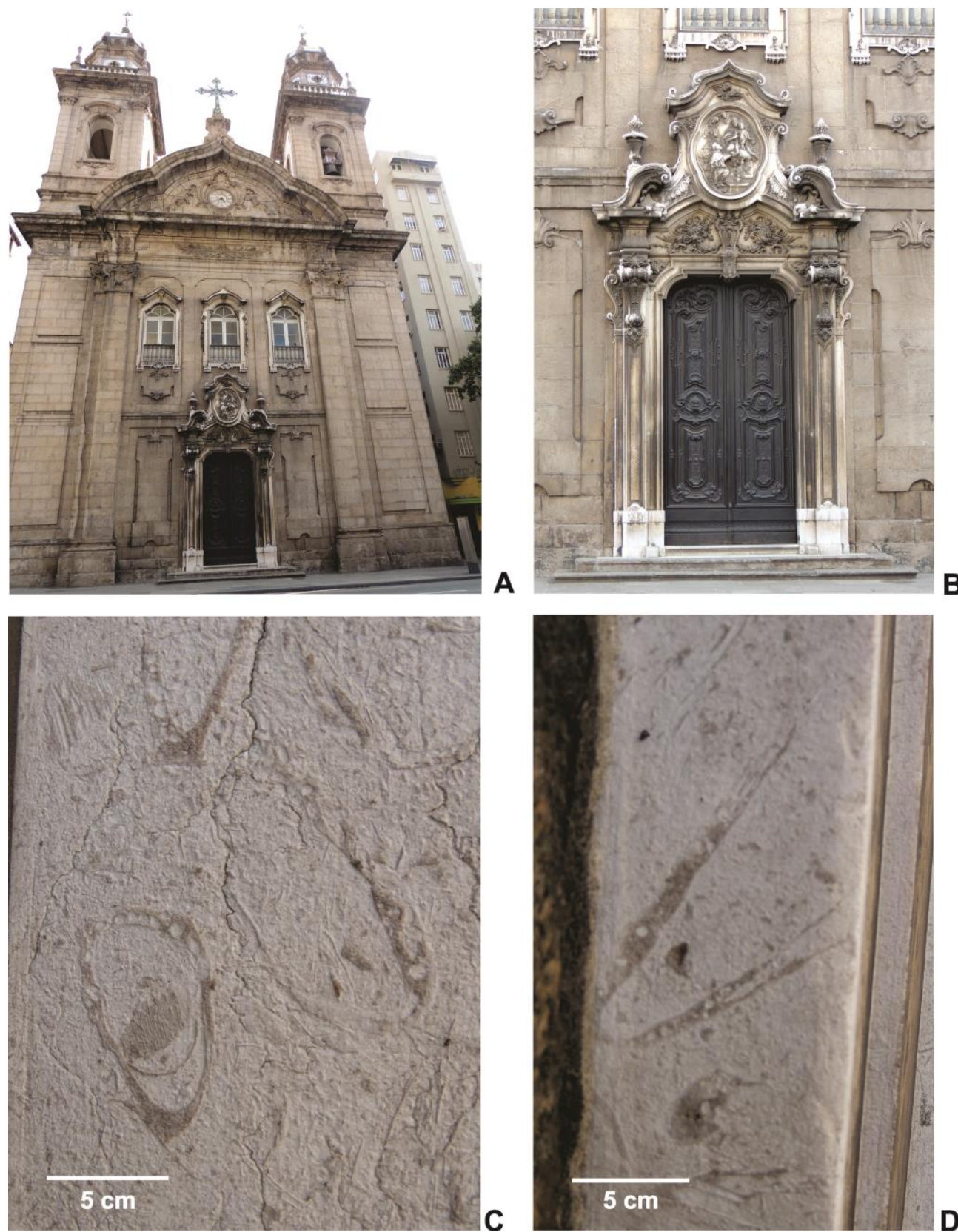

Figura 13. A. Fachada da Igreja Ordem Terceira do Carmo. B. Cantaria da porta principal com o medalhão em Calcário Lioz. C. Corte transversal de fósseis do gênero Caprinula D`Orbigny, 1847, mostrando os canais piriformes. D. Corte longitudinal de fóssil do gênero Caprinula D`Orbigny, 1847. 


\section{Ponto 5: Rua da Assembleia, $n^{0} 31$ e Rua do Carmo, no 8.}

Esse ponto é composto por dois prédios na Rua da Assembléia no 31 e, o segundo, logo em seguida, virando à esquerda na Rua do Carmo $\mathrm{n}^{\circ}$ 8. Suas fachadas são muito semelhantes, compostas por travertino, muito usado em construção, tanto no passado como na atualidade, em função de sua durabilidade, fácil aplicação e estética.

Segundo Folk (1993) e Ford \& Pedley (1996), esse calcário, de coloração variando entre o bege e o branco, é formado originariamente em águas termais e apresenta apenas atividade microbiana, principalmente bactérias tolerantes ao calor, e diatomáceas, todavia não possuem vestígios de vegetais ou animais.

Todavia, foram encontrados estromatólitos centimétricos, além de muitos vugs, ou seja, pequenas cavidades na rocha com uma linha mineral de composição diferente da rocha circundante, com possíveis vestígios de marcas de raízes e de um molusco bivalve (Figura 14).
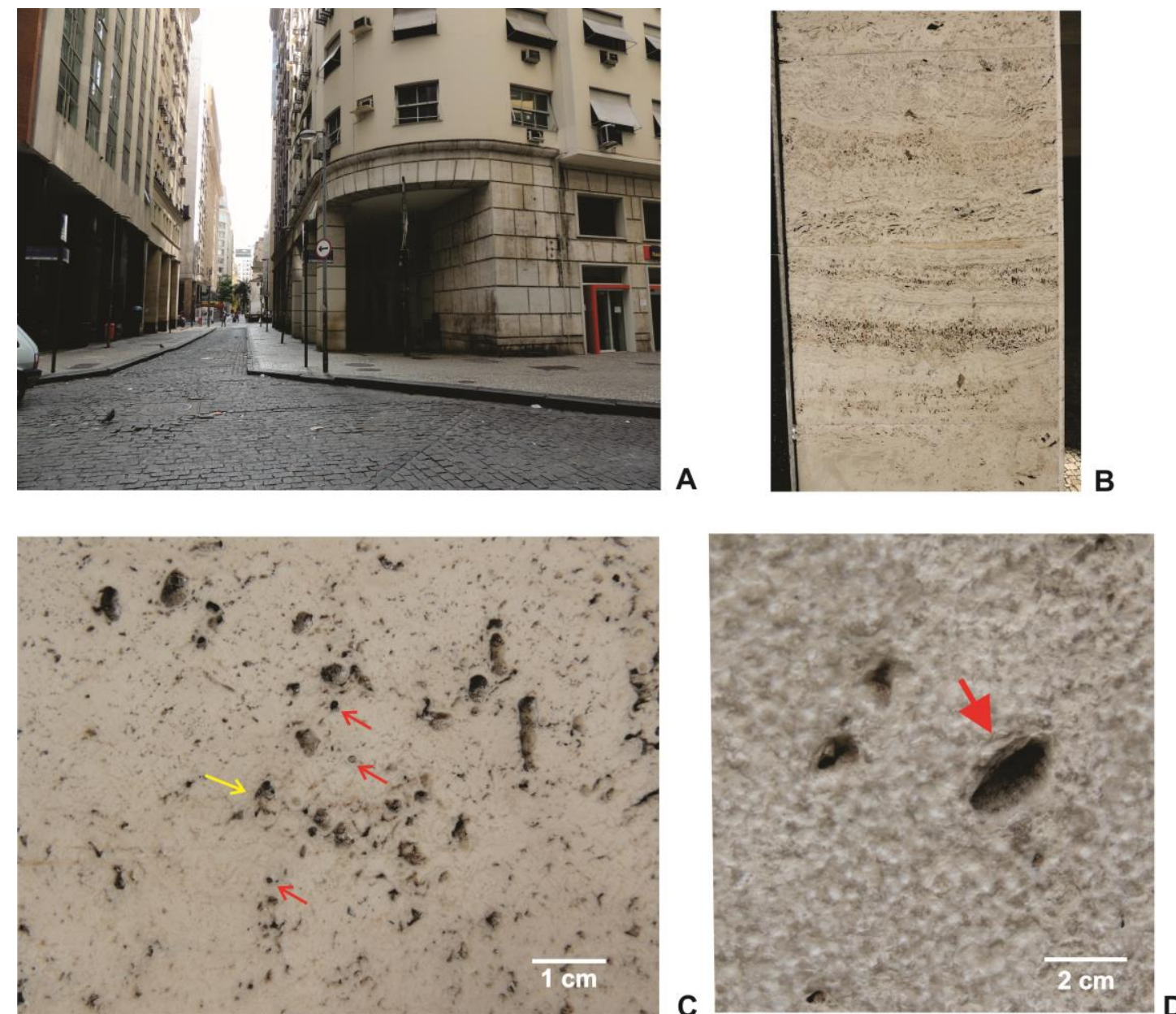

Figura 14. A. Fachadas dos prédios das esquinas da Rua do Carmo e Rua da Assembleia. B. Detalhe do travertino com estruturas sedimentares. C. Vugs tubulares associados a possíveis vestígios de raízes (setas vermelhas) e de Bivalves (seta amarela). D. Molusco Bivalve (seta vermelha).

\section{Ponto 6: Superintendência Regional da Receita Federal - Av. Presidente Antônio Carlos, 375.}

Apresentando fachada tipicamente protomodernista, que justapõe estilo eclético a colunas gregas e ornamentos clássicos, o prédio da Superintendência Regional da Receita Federal (Figura 15 A) foi erguido na esplanada do Castelo durante o período histórico conhecido como Estado Novo, entre 1937 e 1945. O embasamento da edificação é revestido, em sua parte inferior, por placas de granito de coloração avermelhada e, em sua parte superior, por um metacalcário estromatolítico de coloração variando de bege a bem rosada (Figura 15 B). Tais estromatólitos, provavelmente provenientes da Pedreira do Cumbi (MG), apresentam dois padrões distintos 
de crescimento. O primeiro está associado a um crescimento em ambiente mais calmo, no qual as colunas estromatolíticas apresentam espaçamento regular entre si (Figura $15 \mathrm{C}$ ). O segundo padrão evidencia um aspecto disforme das colunas observadas em seção transversal (Figura 15 D), sugerindo a existência de um ambiente mais caótico de crescimento, devido à ação das correntes e ondas, condicionando os corpos estromatolíticos a procurarem um posicionamento de menor esforço para se desenvolverem. No piso da escada e no chão, antes da porta principal, os estromatólitos estão em cortes principalmente longitudinais, semelhantes a faixas paralelas (Figura 16).
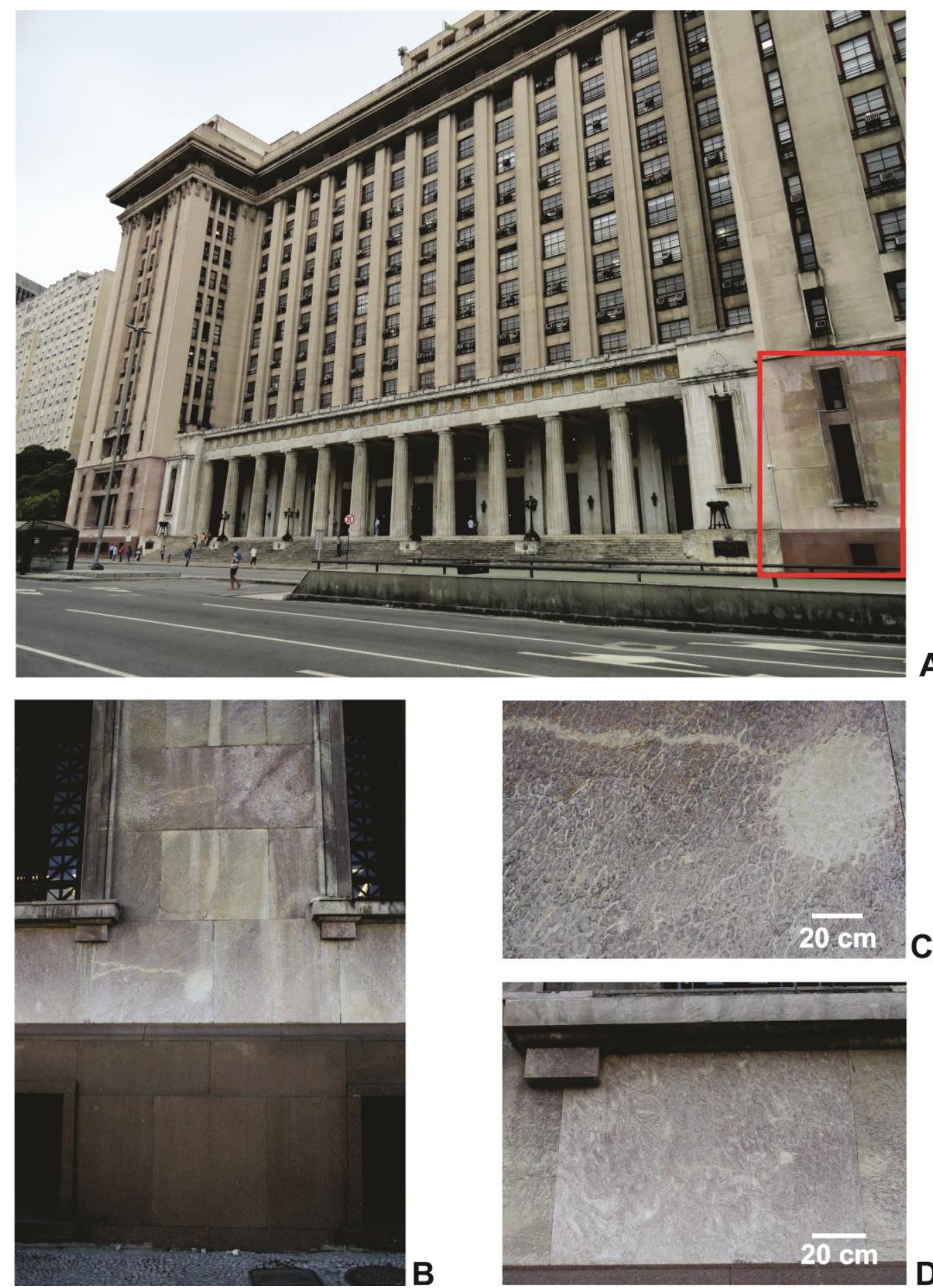

Figura 15. A. Fachada do edifício da Superintendência Regional da Receita Federal. B. Detalhe de parte da fachada. C. Cortes transversais dos estromatólitos desenvolvidos normalmente. D. Os mesmos corpos estromatolíticos deformados em função da adaptação às correntes. 


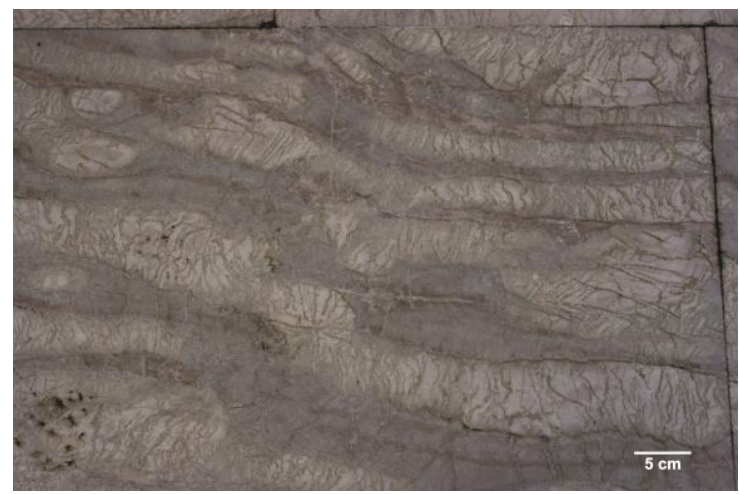

Figura 16. Estromatólitos em cortes longitudinais do piso da escada do edifício da Superintendência Regional da Receita Federal.

\section{Ponto 7: Tribunal Regional do Trabalho -} Av. Presidente Antônio Carlos, 251.

Esse edifício, conhecido como Palácio do Trabalho, inaugurado em 1938 como sede do Ministério do Trabalho, abrigou em 1946 o Tribunal Superior do Trabalho. Em maio de 1988, foi celebrado contrato de comodato com o Ministério do Trabalho, pelo qual a administração do prédio passou a ser do Tribunal Regional do Trabalho.

Exemplo de uma arquitetura préracionalismo, o edifício segue os cânones tradicionais, apresentando avanço nos volumes do embasamento da edificação, mas possui como característica marcante a ausência de ornamentações. Tal embasamento é revestido por placas de metacalcários com estromatólitos colunares, caracterizados por formas circulares e elípticas densamente agrupadas, produzidas por cortes transversais que produzem um padrão semelhante à "pele de onça" (Figura 17). Esses metacalcários com estromatólitos de coloração bege, provavelmente provenientes da Pedreira do Cumbi (MG), contrastam fortemente com o charnoquito escuro utilizado para enfatizar o principal vão de acesso à edificação (Figuras 17 A e B).
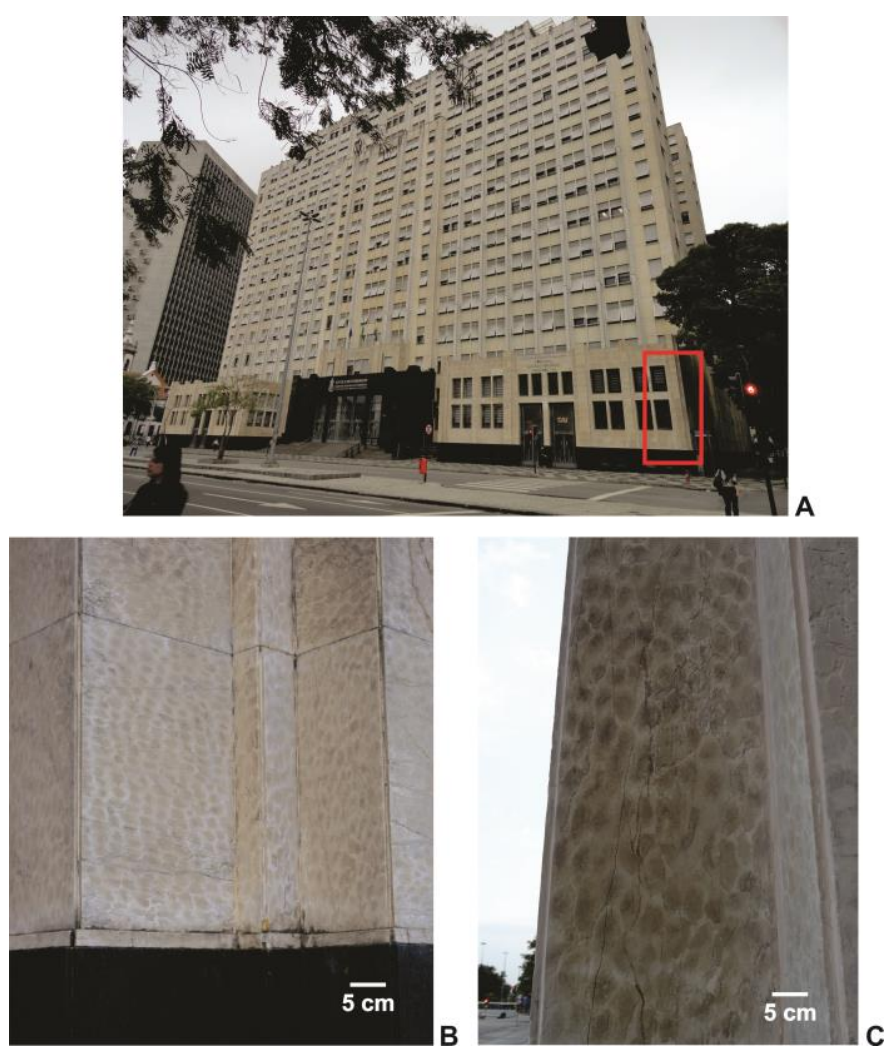

Figura 17. A. Fachada do edifício do Tribunal Regional do Trabalho. B. Estromatólito em corte transversal. C. Detalhe semelhante a "pele de onça". 


\section{Ponto 8: Hospital Geral da Santa Casa da Misericórdia - Rua Santa Luzia, 206.}

A Santa Casa da Misericórdia foi inaugurada em março de 1583, pelo padre José de Anchieta, para atender os doentes da esquadra espanhola de Diogo Flores Baldez, que chegou com a peste a bordo. Sua atual fachada (Figura $18 \mathrm{~A}$ ), resultado das reformas realizadas entre 1840 e 1852, apresenta dois litotipos utilizados para ressaltar os detalhes da construção em meio ao seu corpo principal: Gnaisse Facoidal e Calcário Lioz branco. O Gnaisse Facoidal foi utilizado nos arcos plenos do corpo principal da construção, nas colunas toscanas e no frontão triangular, ao passo que o Lioz branco dá forma aos detalhes desse frontão (Figura 18 B) e à balustrada da varanda (Figuras $18 \mathrm{C}$ e $18 \mathrm{D}$ ).

Para a visualização dos fósseis, é recomendado utilizar um pouco de água para limpar a balaustrada, facilitando, assim, a observação de bivalves rudistas, identificados como pertencentes à Família †Caprinidae e gênero †Caprinula D`Orbigny, 1847, cuja parede da valva livre apresenta uma série de canais paliais internos com formas poligonais e uma série exterior de canais piriformes (Figuras $18 \mathrm{C}$ e $18 \mathrm{D})$.

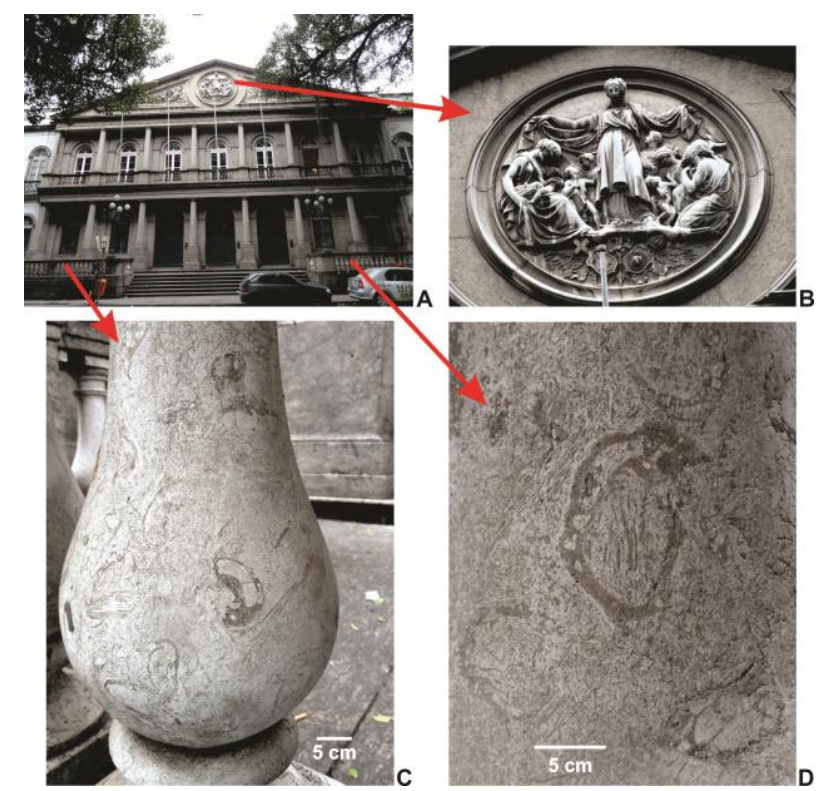

Figura 18. A. Fachada do Hospital Geral da Santa Casa da Misericórdia. B. Detalhe do Medalhão em Lioz do frontão. C e D. Bivalves rudistas do gênero †Caprinula D`Orbigny, 1847.

\section{Ponto 9: Igreja Nossa Senhora de Bonsucesso - Largo da Misericórdia.}

Sua entrada situa-se ao lado da Ladeira da Misericórdia, com calçamento pé-demoleque, ou seja, feito com pedras irregulares. Resta apenas um pequeno trecho da ladeira que subia para o antigo Morro do Castelo (Figura 19 A), local dos primeiros assentamentos, que veio abaixo em 1922.

A Igreja Nossa Senhora de Bonsucesso erguida em 1568, foi reconstruída em 1754 e, atualmente encontra-se totalmente integrada ao conjunto arquitetônico da Santa Casa da Misericórdia. A fachada atual (Figuras 19 A e 19 B), modificada por uma reforma em 1818, apresenta portada setecentista em Calcário Lioz português com fósseis de bivalves rudistas caprinídeos e corais (Figuras 19 C, D e E). O piso alterna áreas nas quais foram utilizados ladrilho hidráulico e um mosaico de mármores de coloração clara e escura. A parte interna da construção apresenta ainda, nos degraus da nave principal, calcário Encarnadão fossilífero de idade cenomaniana, provavelmente originários da região de Terrugem e de Pêro Pinheiro, Norte de Portugal. Esse calcário apresenta como principal conteúdo fossilífero bivalves rudistas, em cortes transversais, da família †Radiolitidae, gênero $\dagger$ Radiolites Lamarck, 1801. Os fósseis destes bivalves, geralmente de grandes tamanhos $(15 \mathrm{a} 25 \mathrm{~cm})$, são evidentes devido ao aspecto espesso e maciço da parede das suas conchas e também à cor esbranquiçada que se destaca no calcário de cor rosa a avermelhada (Figura $19 \mathrm{~F}$ ). 

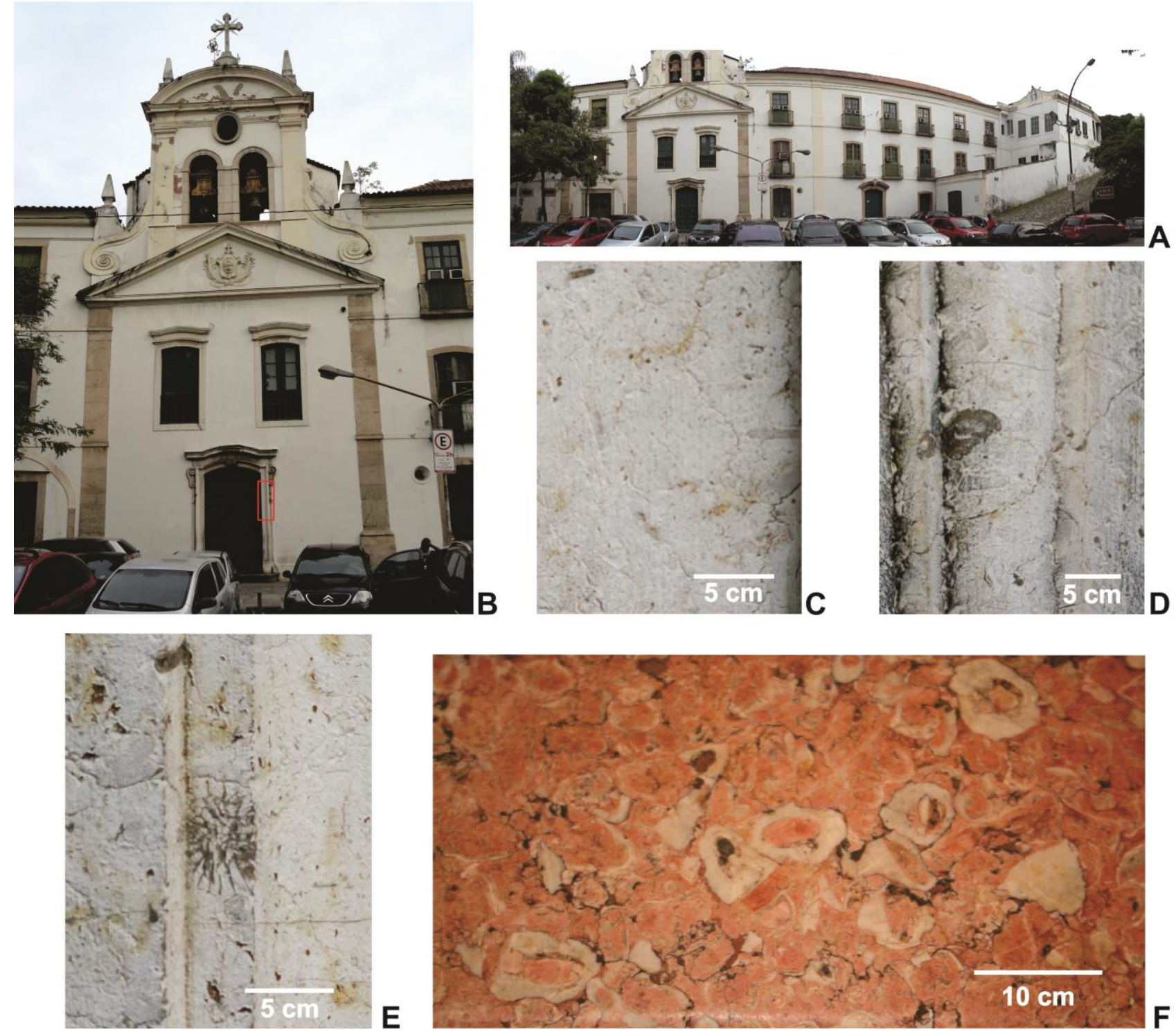

Figura 19. A. Fachada da Igreja Nossa Senhora de Bonsucesso, com parte da ladeira da Misericórdia. B. Detalhe da fachada com Calcário Lioz. C. Bivalve rudista caprinídeos em seção transversal. D e E. Corais solitários em seção transversal. F. Bivalve rudista radiolitídeo em seção transversal.

\section{CONSIDERAÇÕES FINAIS}

$\mathrm{O}$ roteiro proposto para o geoturismo paleontológico é baseado nos fósseis presentes nas rochas utilizadas como revestimento ou piso em prédios do centro histórico do Rio de Janeiro.

As rochas utilizadas foram: Calcários, travertinos, turfas calcárias e metacalcários. As procedências são de Portugal, Itália e Brasil (Minas Gerais).

O litotipo predominante variou de acordo com a evolução da cidade. Inicialmente durante a colônia, $1^{\circ}$ Império e $2^{\circ}$ Império, predominavam os calcários do Cretáceo de Portugal, sendo que a segunda metade do século XIX começou a aparecer nos palacetes particulares e nas igrejas, mármores e travertinos italianos. Durante o período do Estado Novo, boa parte dos prédios públicos utilizou os metacalcários da Pedreira do Cumbi (MG), e, partir da década de 70 do século passado, teve início a importação de mármores, travertinos e calcários de origens de vários lugares do mundo, mas ainda com o predomínio dos originados da Europa, em especial os italianos.

Uma análise preliminar mostra que, em relação à idade de formação, predominam as rochas do Cretáceo, seguido das rochas do Paleoproterozoico, e, por fim, as rochas do Cenozoico.

Os fósseis encontrados foram: estromatólitos, figura bivalves, bivalves 
rudistas caprinídeos e radiolitídeos, corais, esteiras algálicas e marcas de raízes.

Comparando os principais fósseis encontrados, nota-se um equilíbrio na quantidade de rochas com estromatólitos e bivalves rudistas, porém, existe uma quantidade muito reduzida de outros bivalves, corais solitários, esteiras algálicas e marcas de raízes.

Além de valorizar, preservar e proteger a paisagem arquitetônica, histórica e cultural do Rio de Janeiro, o roteiro aqui apresentado permite utilizar as fachadas do centro histórico não só como recurso didático para alunos do ensino básico e superior (em especial dos cursos de geologia, geografia, história, arquitetura e biologia), mas também atinge o público em geral, podendo ser utilizado como uma opção de turismo na Cidade Maravilhosa. Para implementar esse roteiro os professores e guias de turismo podem utilizar tanto folders impressos quanto digitais com as informações necessárias.

\section{AGRADECIMENTOS}

Aos colegas Marcos Antônio Monteiro e Leonardo de Almeida Bernardo, da Divisão de Desenvolvimento da Mineração (DDM) da Superintendência do Rio de Janeiro do Departamento Nacional de Produção Mineral (DNPM-RJ), por todo apoio e pela revisão do texto. Ao estagiário Bruno Jesus de Oliveira Aguiar pelo auxílio técnico em algumas figuras.

\section{REFERÊNCIAS BIBLIOGRÁFICAS}

1. ALMEIDA, S. \& PORTO JR, R. Cantaria e pedreiras históricas do Rio de Janeiro: instrumentos potenciais de divulgação das Ciências Geológicas. Terra e Didática, vol. 8, n. 1, p. 3-23, 2012.

2. AUGUSTO, W.C. \& DEL LAMA, E.A. Roteiro geoturístico no centro da cidade de São Paulo. Terra \& Didática, vol. 7, n. 1, p. 29-40, 2011.

3. AZEVEDO M. Rio de janeiro, sua história, movimentos, homens notáveis, usos e costumes. Vol. I, B.L. Garnier Ed. 448 p., 1877.

4. BABINSH, M; CHEMALE, F.; VAN SCHMUS, W.R. Cronoestratigrafia do Supergrupo Minas e Provável Correlação de Suas Formações Ferríferas com Similares da África do Sul e Austrália. Geochim Brasil, vol. 9, n. 1, p. 33-46, 1995.

5. BAIRD, D. Guide to the geology and scenery of the National Capital Area. Geological Survey of Canada, Miscellaneous Report 15, 188 p., 1968.

6. BARREIROS, E.C. Atlas da Evolução Urbana da Cidade do Rio de Janeiro - Ensaio (1565-1965). Instituto Histórico e Geográfico Brasileiro, 28 p., 1965.

7. BÉLANGER, J. Urban geology of Canada's National Capital area. In: KARROW, P.F. \& WHITE, O.L. (Coordenadores), Urban geology of Canadian Cities: Geological Association of Canada, Special Paper 42, p. 365-384, 1998.

8. BRANDÃO, J.M. Proposta para a criação de um "museu da pedra" na região de Montelavar-Pero Pinheiro (Concelho de Sintra). Cadernos de Sociomuseologia, v. 8, p. 109-115, 1996.

9. BOGGIANI, P.C. Aplicação do conceito de geoparque da UNESCO no Brasil e relação com o SNUC - Sistema Nacional de Unidades de Conservação. Revista Patrimônio Geológico e Cultura, v. 1, n. 1, p.1-4, 2010.

10. M. Cachão; C.M. Silva; M.J. Ribeiro. 2009. Cemitério de São Sebastião. Geoalverca. Disponível em: http://geoalverca.ucoz.com/georoteiro/10_cemiterio.pdf. Acessado em: 05fev2016.

11. CARVALHO, H.L. Patrimônio geológico no Centro Histórico de Natal. Natal, 2010. 120 p (Relatório de Graduação) - Centro de Ciências Exatas e da Terra, Universidade Federal do Rio Grande do Norte. 12. DECHASEAUX, C.; COOGAN, A.; COX, L. Systematic descriptions : Hippuritoida. In: MOORE, R.C. \& TEICHERT, C. (Coordenadores), Treatise on Invertebrate Paleontology, 2. Geological Society of America and University of Kansas Press, p. 803-817, 1969.

13. FERNANDES, M.A.; FRANCISCHINI FILHO, H.R.; CARVALHO, I.S. Paleoicnologia Urbana: O Patrimônio Fossilífero de Araraquara, Estado de São Paulo, Brasil. Memórias e Notícias, vol. 3, n. Nova Série, p. 455-462, 2008.

14. FOLK, R.L. 1993. SEM imaging of the bactéria and nannobacteria in carbonate sediments and rocks. Journal of Sedimentary Petrology, vol. 63, n. 5, p. 990-999, 1993.

15. FORD, T.D. \& PEDLEY, H.M. A review of tufa and travertine deposits of the world. Earth-Science Reviews, vol. 41, p. 117-115, 1996.

16. KUZMICKAS, L. \& DEL LAMA, E.A . Roteiro Geoturístico pelo Cemitério da Consolação, São Paulo. Revista Geociências UNESP, vol. 34, n. 1, p. 41-54, 2015.

17. LÉRY, J. Viagem à terra do Brasil. São Paulo. Livraria Martins Fontes, 278 p., 1941.

18. LICCARDO A.; PIEKARZ G.F., SALAMUNI E. Geoturismo em Curitiba. Curitiba: Mineropar, 122p., 2008.

19. MANSUR, K.L.; CARVALHO, I.S.; DELPHIM, C.F.M.; BARROSO, E.V. O Gnaisse facoidal: a mais carioca das rochas. Anuário do Instituto de Geociências - UFRJ, vol. 31, n. 2, p. 9-22, 2008. 
20. MEllo MORAIS A. J. Chronica Geral do Brasil - 1500-1700. Tomo I. LGarnier Ed. 622 p., 1886.

21. MENEZES, S.O. Descoberta, observação, interpretação e educação (geo)ambiental: um exemplo de geologia "urbana" no Santa Cruz Shopping, Juiz de Fora, Estado de Minas Gerais. Virtú (UFJF), vol. 6, p.1-12, 2007.

22. PEREIRA, C.A. \& LICCARDO, A. Rochas e Cantaria usadas no Barroco Mineiro. Revista Patrimônio Geológico e Cultura, vol. 1, n. 1, p.1-2, 2010.

23. PINTO, A.B.C. Geodiversidade e Patrimônio Geológico de Salvador: uma diretriz para a geoconservação e a educação em geociências. Salvador, 2015. 228 p. Tese (Doutorado em Ciências) Instituto de Geociências, Universidade Federal da Bahia. 24. PINTO, A.B.C.; ROSATO, C.S.O.; RIOS, D.C.; BARRETOS, J.M.C.; OLIVEIRA, N.S.A. Rochas ornamentais na geologia urbana: Uma das sete maravilhas de origem portuguesa no mundo. Revista Electrônica de Ciências da Terra, vol. 15, n.54, p.1-4, 2010.

25. ROBINSON E. A geological walk around the City of London - Royal Exchange to Aldgate. Proceedings of the Geologists Association, vol. 93, p. 225-246, 1982.

26. ROBINSON E. A geological walk in Southwark. Proceedings of the Geologists Association, vol. 104, p. 285-299, 1993.

27. SALLUN FILHO, W. \& FAIRCHILD, T.R. Um passeio pelo passado no shopping: Estromatólitos no Brasil. Revista Ciência Hoje, vol. 37, n. 222, p. 22-29, 2005.

28. SILVA, A. Patrimônio histórico, arquitetônico e cultural. Porto Maravilha, Cidadania e Cultura. Revista Porto Maravilha, vol, 4, p. 5, 2011.
29. SILVA, A. Porto Maravilha e inclusão sócioprodutiva. O Porto Maravilha e os Desafios da Reintegração Econômica da Região na Dinâmica da Cidade, vol. 3, p. 13-15, 2013.

30. C.M. SILVA. 2007. Fósseis na cidade. Paleontologia e Geologia urbanas em Almada. Disponível em

http://paleoviva.fc.ul.pt/almafossil/index/rcapleit.htm. Acessado em: 05fev2014

31. SILVA, C.M. "Fósseis ao Virar da Esquina": Um percurso pela Paleontologia e pela

32. geodiversidade urbana de Lisboa. Paleolusitana, vol. 1, p. 459-463, 2009.

33. SRIVASTAVA N.K. Estromatólitos. In: CARVALHO, I.S. (Coordenador) Paleontologia, Rio de Janeiro: Editora Interciência, p. 171-195, 2004.

34. STERN, A.G.; RICCOMINI, C.; FAMBRINI, G.L.; CHAMANI, M.A.C. Roteiro geológico pelos edifícios e monumentos históricos do centro da cidade de São Paulo. Revista Brasileira de Geociências, vol. 36, n. 4, p. 704711, 2006.

35. STEUBER, T. \& LÖSER, H. Species richness and abundance patterns of Tethyan Cretaceous rudist bivalves (Mollusca; Hippuritacea) in the central-eastern Mediterranean and Middle East, analysed from a paleontological database. Palaeogeography, Paleoclimatology, Palaeoecology, vol. 162, p. 75-104, 2000.

36. THÉVET, A. Singularidades da França Antarctica. São Paulo, Cia. Editora Nacional, 320 p., 1944.

Manuscrito recebido em: 12 de Maio de 2016 Revisado e Aceito em: 05 de Outubro de 2016 